\title{
Commentary: Adherence with a low-FODMAP diet in irritable bowel syndrome: are eating disorders the missing link?
}

\author{
Bruno P. Chumpitazi ${ }^{1,2 *}$, Ligia Alfaro-Cruz ${ }^{1,2}$, Jasmine K. Zia ${ }^{3}$, Robert J. Shulman $^{1,2}$ and \\ Margaret M. Heitkemper 4 \\ ${ }^{1}$ Department of Pediatrics, Baylor College of Medicine, Houston, TX, United States, ${ }^{2}$ Children's Nutrition Research Center, \\ United States Department of Agriculture, Houston, TX. United States, ${ }^{3}$ Department of Gastroenterology, Swedish Medical \\ Center, Seattle, WA, United States, ${ }^{4}$ School of Nursing, Biobehavioral Nursing and Health Systems, University of \\ Washington, Seattle, WA, United States
}

Keywords: FODMAP, irritable bowel syndrome, eating disorder, diet, adherence

\section{A Commentary on}

Adherence with a low-FODMAP diet in irritable bowel syndrome: are eating disorders the missing link?

OPEN ACCESS

Edited by:

Lidia Santarpia,

University of Naples Federico II, Italy

Reviewed by:

Sharon Ross,

National Cancer Institute (NCl),

United States

Alison Colquhoun,

University of São Paulo, Brazi

*Correspondence:

Bruno P. Chumpitazi

chumpita@bcm.edu

Specialty section:

This article was submitted to

Clinical Nutrition

a section of the journal

Frontiers in Nutrition

Received: 03 May 2019

Accepted: 12 August 2019

Published: 04 September 2019

Citation:

Chumpitazi BP, Alfaro-Cruz L, Zia JK,

Shulman RJ and Heitkemper MM

(2019) Commentary: Adherence with

a low-FODMAP diet in irritable bowel

syndrome: are eating disorders the

missing link? Front. Nutr. 6:136.

doi: 10.3389/fnut.2019.00136 by Mari, A., Hosadurg, D., Martin, L., Zarate-Lopez, N., Passananti, V., and Emmanuel, A. (2019). Eur J Gastroenterol Hepatol. 31:178-82. doi: 10.1097/MEG.0000000000001317

A low fermentable oligosaccharide disaccharide monosaccharide and polyols (FODMAP) diet has demonstrated efficacy in ameliorating adult and pediatric irritable bowel syndrome (IBS) symptoms $(1,2)$. Though not formally studied, in clinical practice a traditional low FODMAP diet is applied in three phases (restriction, re-introduction, personalized maintenance) (3). Working with a dietitian knowledgeable about a low FODMAP diet is strongly recommended. There are potential relative contraindications to following a traditional low FODMAP diet given its potential effects on nutritional status, one of which includes an active eating disorder (4).

Eating disorder behavior was recently evaluated by Mari et al. using the SCOFF instrument within a population of adults with irritable bowel syndrome (IBS) who were instructed to begin a low FODMAP diet (5). The included subjects had failed previous IBS interventions (5). Based on the SCOFF results and measured adherence, the authors suggest that strict adherence to a low FODMAP diet should raise the suspicion of a possible underlying eating disorder. Though being aware of a possible eating disorder in any population is certainly important, particularly when dietary modification is being advised, we urge some discretion when making this conclusion.

There are aspects regarding diet in the IBS population that should be considered. In children, adolescents, and adults with IBS, diet exacerbates IBS symptoms in greater than 80 percent (6-8). Dietary self-perceived food intolerances are associated with increased severity of both IBS symptoms and decreased quality of life $(6,8,9)$. A majority of children and adults with IBS alter their diets and/or are interested in learning which foods to avoid (9-12). In this light, some of the questions asked in the SCOFF instrument may not point toward eating disorder behavior in those with IBS as much as the perception that diet is an important factor affecting both IBS symptoms and quality of life. These questions include: "Would you say that food dominates your life?" and "Do you worry you have lost control over how much you eat?" We note that both of these questions were the two most frequently endorsed by subjects in the Mari et al. study (5). Ultimately, though not assessed, the relationship between endorsing some of the SCOFF questions and low FODMAP diet adherence in those with IBS may be less related to addressing potential eating disorder perceptions 
(e.g., distorted body image) or behaviors (e.g., restrictive eating) and more related to stronger motivation to address self-perceived food related IBS symptoms.

Stronger motivation and several other factors such as decision making, self-efficacy, socioeconomic contexts, cultural contexts, food access, and education have been shown to affect dietary regimen adherence (13). These and other potentially important factors were not evaluated in the Mari et al. study. Future studies of dietary regimen adherence in those with IBS may consider evaluating both these factors and the perception of food triggers as a source of symptoms $(9,13)$.

The use of the SCOFF instrument is an additional aspect which one may be consider when interpreting the Mari et al. study results. The SCOFF instrument is a screening questionnaire and not the gold-standard either for diagnosing an eating disorder or for determining the presence of eating disorder behavior (14). Due to the prevalence of eating disorders in the general population, the positive predictive value of the SCOFF instrument in identifying an eating disorder is less than $25 \%$ (15). To our knowledge, the SCOFF instrument has not been validated in populations where diet may play an important role (e.g., those with IBS or celiac disease). Furthermore, it has been recommended that positive results of the SCOFF instrument be

\section{REFERENCES}

1. Halmos EP, Power VA, Shepherd SJ, Gibson PR, Muir JG. A diet low in FODMAPs reduces symptoms of irritable bowel syndrome. Gastroenterology. (2014) 146:67-75 e5. doi: 10.1053/j.gastro.2013.09.046

2. Chumpitazi BP, Cope JL, Hollister EB, Tsai CM, McMeans AR, Luna RA, et al. Randomised clinical trial: gut microbiome biomarkers are associated with clinical response to a low FODMAP diet in children with the irritable bowel syndrome. Aliment Pharmacol Ther. (2015) 42:418-27. doi: 10.1111/apt.13286

3. Whelan K, Martin LD, Staudacher HM, Lomer MCE. The low FODMAP diet in the management of irritable bowel syndrome: an evidence-based review of FODMAP restriction, reintroduction and personalisation in clinical practice. J Hum Nutr Diet. (2018) 31:239-55. doi: 10.1111/jhn.12530

4. Halmos EP, Gibson PR. Controversies and reality of the FODMAP diet for patients with irritable bowel syndrome. J Gastroenterol Hepatol. (2019).34:1134-42. doi: 10.1111/jgh.14650

5. Mari A, Hosadurg D, Martin L, Zarate-Lopez N, Passananti V, Emmanuel A. Adherence with a low-FODMAP diet in irritable bowel syndrome: are eating disorders the missing link? Eur J Gastroenterol Hepatol. (2019) 31:178-82. doi: 10.1097/MEG.0000000000001317

6. Chumpitazi BP, Weidler EM, Lu DY, Tsai CM, Shulman RJ. Self-perceived food intolerances are common and associated with clinical severity in childhood irritable bowel syndrome. J Acad Nutr Diet. (2016) 116:1458-64. doi: 10.1016/j.jand.2016.04.017

7. Reed-Knight B, Squires M, Chitkara DK, van Tilburg MA. Adolescents with irritable bowel syndrome report increased eating-associated symptoms, changes in dietary composition, and altered eating behaviors: a pilot comparison study to healthy adolescents. Neurogastroenterol Motil. (2016) 28:1915-20. doi: 10.1111/nmo.12894

8. Bohn L, Storsrud S, Tornblom H, Bengtsson U, Simren M. Self-reported foodrelated gastrointestinal symptoms in IBS are common and associated with more severe symptoms and reduced quality of life. Am J Gastroenterol. (2013) 108:634-41. doi: 10.1038/ajg.2013.105

9. Harris LA, Umar SB, Baffy N, Heitkemper MM. Irritable bowel syndrome and female patients. Gastroenterol Clin North Am. (2016) 45:179-204. doi: 10.1016/j.gtc.2016.02.001 followed by further evaluation (including questions regarding behavior) before referral to a mental health specialist (14). None of the subjects in the Mari et al. study were reported to have undergone further evaluation to determine whether either an eating disorder or related eating disorder behavior was present.

In conclusion, the findings by Mari et al. should spur further clinical investigation related to dietary adherence in IBS. However, given both the role of diet in IBS and the methodological approach employed, we suggest caution in interpreting the findings to suggest adherence to a low FODMAP diet is strongly associated with eating disorder behavior.

\section{AUTHOR CONTRIBUTIONS}

$\mathrm{BC}$ conceived, wrote, and revised the manuscript. The remaining authors contributed to the writing and critically revised the manuscript. All authors gave their final approval.

\section{FUNDING}

Intellectual support was provided by National Institutes of Health DK101688, DK117219, NR014479, NR013497, and DK056338.
10. Halpert A, Dalton CB, Palsson O, Morris C, Hu Y, Bangdiwala S, et al. What patients know about irritable bowel syndrome (IBS) and what they would like to know. National Survey on Patient Educational Needs in IBS and development and validation of the Patient Educational Needs Questionnaire (PEQ). Am J Gastroenterol. (2007) 102:1972-82. doi: 10.1111/j.1572-0241.2007.01254.x

11. Monsbakken KW, Vandvik PO, Farup PG. Perceived food intolerance in subjects with irritable bowel syndrome- etiology, prevalence and consequences. Eur J Clin Nutr. (2006) 60:667-72. doi: 10.1038/sj.ejcn.16 02367

12. Carlson MJ, Moore CE, Tsai CM, Shulman RJ, Chumpitazi BP. Child and parent perceived food-induced gastrointestinal symptoms and quality of life in children with functional gastrointestinal disorders. J Acad Nutr Diet. (2014) 114:403-13. doi: 10.1016/j.jand.2013.10.013

13. Sherman AM, Bowen DJ, Vitolins M, Perri MG, Rosal MC, Sevick MA, et al. Dietary adherence: characteristics and interventions. Control Clin Trials. (2000) 21:206S-11S. doi: 10.1016/S0197-2456(00)00080-5

14. Hill LS, Reid F, Morgan JF, Lacey JH. SCOFF, the development of an eating disorder screening questionnaire. Int J Eat Disord. (2010) 43:344-51. doi: 10.1002/eat.20679

15. Luck AJ, Morgan JF, Reid F, O'Brien A, Brunton J, Price C, et al. The SCOFF questionnaire and clinical interview for eating disorders in general practice: comparative study. BMJ. (2002) 325:755-6. doi: 10.1136/bmj.325.73 67.755

Conflict of Interest Statement: The authors declare that the research was conducted in the absence of any commercial or financial relationships that could be construed as a potential conflict of interest.

Copyright (c) 2019 Chumpitazi, Alfaro-Cruz, Zia, Shulman and Heitkemper. This is an open-access article distributed under the terms of the Creative Commons Attribution License (CC BY). The use, distribution or reproduction in other forums is permitted, provided the original author(s) and the copyright owner(s) are credited and that the original publication in this journal is cited, in accordance with accepted academic practice. No use, distribution or reproduction is permitted which does not comply with these terms. 